\title{
Obstructive sleep apnea knowledge and attitudes among recent medical graduates training in Ecuador
}

\author{
Iván Chérrez-Ojeda ${ }^{1,2^{*}} \mathbb{D}$, Juan Carlos Calderón ${ }^{1,2}$, Andrea Fernández García ${ }^{2}$, Donna B. Jeffe ${ }^{3}$, Ilka Santoro ${ }^{4}$, \\ Emanuel Vanegas ${ }^{1,2}$, Annia Cherrez ${ }^{5}$, José Cano ${ }^{1,2}$, Freddy Betancourt ${ }^{2}$ and Daniel Simancas-Racines ${ }^{6}$
}

\begin{abstract}
Background: We aimed to assess recent Latin American medical school graduates' knowledge and attitudes about OSA and examine whether their knowledge and attitudes about OSA differed from practicing physicians.

Methods: Recent medical graduates completed the Spanish translation of the OSA Knowledge and Attitudes (OSAKA) questionnaire at the 2013 national primary-care residency-placement meeting in Ecuador. The OSAKA includes 18 knowledge and five attitudinal items about OSA. We compared recent graduates' data with data collected in 2010-2011 from practicing physicians using chi-square tests of associations among categorical variables and analysis of variance of differences in mean knowledge and attitude scores. Unadjusted logistic regression models tested the odds that recent graduates (vs. practicing physicians) answered each item correctly.

Results: Of 265 recent graduates, 138 (52.1\%) were male, and mean age was 25.9 years. Although mean knowledge was low overall, scores were lower for recent graduates than for the 367 practicing physicians (53.5\% vs. $60.4 \% ; p<0.001$ ). Practicing physicians were significantly more likely to answer specific items correctly with one exception-recent graduates were more likely to know that $<5$ apneas-hypopneas/h is normal (OR 1.47, 1. 03-2.07). Physicians in practice attributed greater importance to OSA as clinical disorder and the need for identifying patients with OSA; but recent graduates reported greater confidence in managing patients with OSA and CPAP.

Conclusions: OSA-focused educational interventions during medical school should help to improve recent medical graduates' abilities to diagnose and treat OSA. We recommend a greater number of hours of medical students' exposure to sleep education.
\end{abstract}

Keywords: Obstructive sleep apnea, Medical student, Knowledge, Physician, Questionnaire, OSAKA

\section{Background}

Obstructive sleep apnea (OSA) is defined as repeated episodes of upper airway closure during sleep, resulting in oxy-hemoglobin desaturation and sleep fragmentation. This produces diurnal sleepiness and can lead to cognitive impairment and cardiovascular morbidity [1]. An estimated $2-4 \%$ of the middle-aged population is affected $[2,3]$. OSA has been identified as an independent risk factor for hypertension, cardiovascular disease, abnormalities in glucose

\footnotetext{
* Correspondence: ivancherrez@gmail.com

'Universidad Espiritu Santo, Samborondon, Ecuador

${ }^{2}$ Respiralab Research Group, Respiralab, Guayaquil, Ecuador

Full list of author information is available at the end of the article
}

metabolism, depression and sleepiness-related accidents $[4,5]$. Diagnoses can be made through full-night sleep studies in clinic or at home using polysomnography (PSG) or respiratory polygraph. OSA at any level of severity is reported to lead to impairment in patients' quality of life [6]. Continuous positive airway pressure (CPAP) is the gold standard treatment [7]. There are medical morbidities, including new-onset cardiovascular disease and hypertension [8]. In Latin American countries, use of these treatments for OSA is limited, not only due to cost, but also to lack of physicians' knowledge about OSA [9], which impedes diagnosis and treatment of the disease. 
The low physicians' knowledge and its clinical suspicion about OSA lead to under diagnosis [10, 11]. Few studies have examined whether length of physicians' practice experience is associated with knowledge and attitudes about OSA, and its treatment [9, 12-15]. Recent studies in China and Saudi Arabia have assessed medical students' knowledge about sleep disorders, but neither study specifically measured knowledge about OSA and its treatment $[16,17]$.

A recent study of Latin American general practitioners found no significant association between knowledge of OSA and number of years in practice [9], suggesting an overall lack of sleep medicine content in the medical school curriculum in Latin American countries over time. In Ecuador, Universities have $40 \mathrm{~h}$ of Respiratory Medicine curriculum and only $10 \%$ are dedicated to teach sleep apnea. The level of medical students' knowledge of OSA at the time of graduation, therefore, can provide insight into their future medical practice in diagnosing OSA and prepare them to be alert when a patient presents with possible sleep apnea.

Thus, the objective of our present study was to assess the knowledge and attitudes of recent Latin American medical school graduates using a validated questionnaire. We compared these results with knowledge of General Physician in order to determinate if this knowledge is lower and if the reason could be an inadequate sleep education curriculum during medical school.

\section{Methods}

\section{Study design}

In 2013, we conducted an anonymous, cross-sectional survey of recent medical school graduates from both public and private universities in Ecuador as well as Ecuadorian students who attended foreign universities in Cuba and the Dominican Republic. All these universities have medical schools accredited by the government of Ecuador. In 2013, the surveys were administered during an annual, national meeting in Guayaquil for allocation of community service placement at primary care settings across Ecuador. Every year, about 1000 recent medical graduates attend this annual meeting. Community service is a requirement in Ecuador in order to obtain a professional license to practice. The institutional review board at the Kennedy Clinic at Guayaquil approved the study. Participants provided verbal consent to participate in the study before completing the questionnaire. No financial incentive was offered, and participation was voluntary.

\section{Study survey}

We used the Spanish-translation of the OSAKA questionnaire [9] that was previously developed and validated in English in the USA [12,13] to assess physicians' knowledge and attitudes concerning the identification and management of patients with OSA. The OSAKA questionnaire includes 18 knowledge items and five questions related to attitudes about OSA. The knowledge items covered different OSA domains about epidemiology, pathophysiology, symptoms, diagnosis, and treatment.

Options for answers to knowledge questions were "true," "false," or "do not know," which was scored as an incorrect response. Total knowledge scores were computed as the percentage of correct answers to the 18 knowledge questions and ranged from zero to $100 \%$. Two attitude questions asked about importance of OSA, and responses were scored on a 5-point Likert scale, ranging from not important [1] to extremely important [5]. The other three attitude questions dealt with one's confidence in diagnosing and treating patients with OSA, and responses were scored from strongly disagree [1] to strongly agree [5]. Mean scores were computed for each of the two attitude scales.

\section{Data analysis}

All fully completed questionnaires were included in the analysis. Descriptive statistics were used to summarize answers to each question about knowledge (frequency and percentage answering correctly) and attitudes (mean and standard deviation [SD]). We merged data from our sample of recent medical school graduates with data collected in 2010-2011 for a study of practicing physicians in Latin American countries [9] to compare knowledge and attitudes for recent graduates vs. physicians already in practice. To help us target areas for sleep education curriculum design during medical school, we used chi-square tests to examine the proportions of different comparison groups who answered each knowledge item correctly: 1) recent graduates vs. physicians in practice, and for recent graduates only, students who graduated from private vs. public universities. Analyses of variance (ANOVAs) also were used to examine differences in the mean scores for knowledge and attitudes (importance of OSA and confidence) by each of these comparison groups. Unadjusted logistic regression models were used to determine odds of answering each item correctly comparing recent graduates with practicing physicians. Statistical tests were performed using SPSS version 19 (IBM SPSS, Inc., Chicago, IL, 2000). A two-tailed $P<$ 0.05 was considered significant for all tests.

\section{Results}

Out of 939 graduates who attended the meeting, 265 (28.2\%) completed the entire survey. Most of the participants were male $(52.1 \%)$ and graduated from public 
universities (80.2\%); participants were 25.9 years old, on average (SD, 3.0).

\section{Knowledge}

None of the questions was answered correctly by all participants (Fig. 1). Overall, the item that was answered incorrectly by most respondents was, "Laserassisted uvuloplasty is an appropriate treatment for severe OSA," and the item answered correctly by most respondents was, "The most common cause of OSA in children is the presence of large tonsils and adenoids." As shown in Table 1, the proportions of recent graduates answering each item correctly varied widely.

Eleven items measuring knowledge of diagnosis, treatment, and clinical outcomes of OSA were answered correctly by a greater proportion of practicing physicians compared with recent medical graduates (Fig. 1). The mean knowledge score was lower for recent graduates than for physicians in practice $(53.5 \% \mathrm{vs}$. $60.4 \% ; p<0.001$ (Fig. 2). Although low for both groups, a greater proportion of recent medical graduates than practicing physicians (33.2\% vs $25.3 \%$ ) knew that less than 5 apneas or hypopneas per hour is normal in adults (Table 1).

As shown in Table 2, a lower proportion of recent graduates from public compared with private universities correctly answered the questions about patients with OSA snore (item $4,85 \%$ vs. $96.1 \% ; p<0.05$ ) and a collar size in men greater than $17 \mathrm{in}$. being associated with OSA (item $14,24.3 \%$ vs. $47.1 \% ; p<0.01$ ). No significant differences were observed in mean knowledge scores by medical-school ownership (Table 2).

\section{Importance of OSA and confidence in identifying and managing OSA}

In our study, $44.2 \%$ of the students considered OSA to be important or extremely important as a clinical disorder. Similarly, $40.4 \%$ considered identifying patients with OSA as important to extremely important. More than half $(60.4 \%)$ of the respondents agreed or strongly agreed that they were confident in identifying patients with OSA. Almost half of participants (46.4\%) agreed or strongly agreed that they were confident in their ability to manage OSA, but just $26.8 \%$ agreed or strongly agreed that they were confident in their ability to manage patients with CPAP therapy.

In general, physicians in practice attributed greater importance to OSA as clinical disorder and to identifying patients with OSA, and they reported greater confidence identifying patients at risk compared with recent graduates; but recent graduates reported greater confidence in managing patients with OSA and CPAP and on the confidence subscale score overall compared with physicians in practice (Table 3). No significant differences by gender, country, or university ownership were observed in attitudes among recent graduates (Table 4).

\section{Discussion}

In our previous study we found no significant difference in total OSA knowledge by years in practice $(<5 \mathrm{vs}>$ 5 years since graduation) and we hypothesized that this phenomenon may reflect a lack of adequate information regarding sleep disorders at the undergraduate and graduate medical education levels [9].

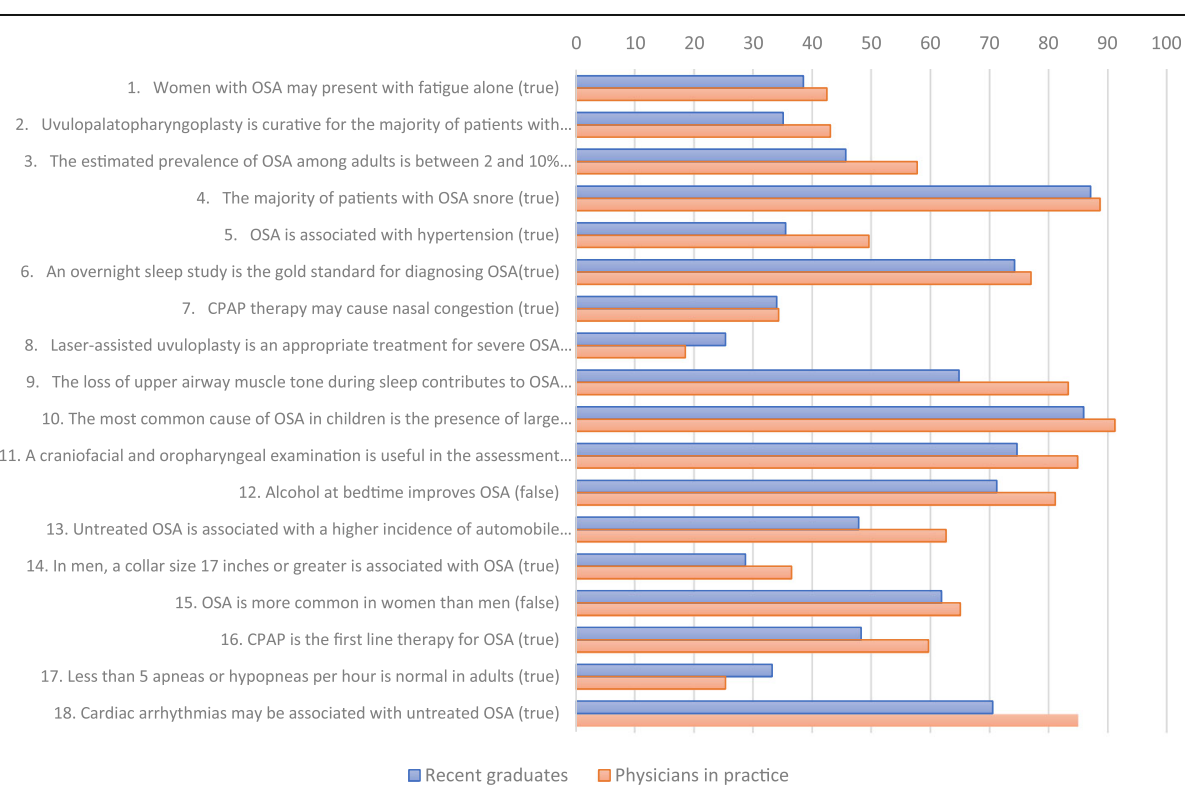

Fig. 1 Percentage of participants reporting correct answers for each OSAKA comparing recent graduates with practicing physicians 
Table 1 Number (\%) of participants reporting correct answers for each OSAKA item and results of unadjusted logistic regression models for each item comparing recent graduates with practicing physicians

\begin{tabular}{|c|c|c|c|c|c|}
\hline \multirow[t]{3}{*}{ Knowledge items } & Recent graduates & $\begin{array}{l}\text { Physicians in } \\
\text { practice }\end{array}$ & Total & \multirow[t]{3}{*}{$p^{*}$} & \multirow[t]{3}{*}{$\begin{array}{l}\text { Crude odds } \\
\text { ratio }(\text { Cl } 95 \%)^{\mathrm{a}}\end{array}$} \\
\hline & $N=265$ & $N=367$ & $N=656$ & & \\
\hline & n (\%) & n (\%) & n (\%) & & \\
\hline 1. Women with OSA may present with fatigue alone (true) & $102(38.5)$ & $156(42.5)$ & $258(40.8)$ & 0.311 & $0.85(0.61-1.17)$ \\
\hline $\begin{array}{l}\text { 2. Uvulopalatopharyngoplasty is curative for the majority of } \\
\text { patients with OSA(false) }\end{array}$ & $93(35.1)$ & $158(43.1)$ & $251(39.7)$ & $<0.05$ & $0.72(0.52-0.99)$ \\
\hline $\begin{array}{l}\text { 3. The estimated prevalence of OSA among adults is between } \\
2 \text { and } 10 \% \text { (true) }\end{array}$ & $121(45.7)$ & $212(57.8)$ & $333(52.7)$ & $<0.01$ & $0.61(0.45-0.85)$ \\
\hline 4. The majority of patients with OSA snore (true) & $231(87.2)$ & $326(88.8)$ & $557(88.1)$ & 0.525 & $0.85(0.53-1.39)$ \\
\hline 5. OSA is associated with hypertension (true) & $94(35.5)$ & $182(49.6)$ & $276(43.7)$ & $<0.001$ & $0.56(0.40-0.77)$ \\
\hline $\begin{array}{l}\text { 6. An overnight sleep study is the gold standard for } \\
\text { diagnosing OSA(true) }\end{array}$ & $197(74.3)$ & $283(77.1)$ & $480(76.0)$ & 0.421 & $0.86(0.60-1.24)$ \\
\hline 7. CPAP therapy may cause nasal congestion (true) & $90(34.0)$ & $126(34.3)$ & $216(34.2)$ & 0.923 & $0.98(0.71-1.37)$ \\
\hline $\begin{array}{l}\text { 8. Laser-assisted uvuloplasty is an appropriate treatment for } \\
\text { severe OSA (false) }\end{array}$ & $67(25.3)$ & $68(18.5)$ & $135(21.4)$ & $<0.05$ & $1.49(1.02-2.18)$ \\
\hline $\begin{array}{l}\text { 9. The loss of upper airway muscle tone during sleep } \\
\text { contributes to OSA (true) }\end{array}$ & $172(64.9)$ & $306(83.4)$ & $478(75.6)$ & $<0.001$ & $0.37(0.25-0.53)$ \\
\hline $\begin{array}{l}\text { 10. The most common cause of OSA in children is the } \\
\text { presence of large tonsils and adenoids (true) }\end{array}$ & $228(86.0)$ & $335(91.3)$ & $563(89.1)$ & $<0.05$ & $0.59(0.36-0.97)$ \\
\hline $\begin{array}{l}\text { 11. A craniofacial and oropharyngeal examination is useful } \\
\text { in the assessment of patients of large tonsils and } \\
\text { adenoids (true) }\end{array}$ & $198(74.7)$ & $312(85.0)$ & $510(80.7)$ & $<0.01$ & $0.52(0.35-0.78)$ \\
\hline 12. Alcohol at bedtime improves OSA (false) & $189(71.3)$ & $298(81.2)$ & $487(77.1)$ & $<0.01$ & $0.58(0.40-0.84)$ \\
\hline $\begin{array}{l}\text { 13. Untreated OSA is associated with a higher incidence of } \\
\text { automobile crashes (true) }\end{array}$ & $127(47.9)$ & $230(62.7)$ & $357(56.5)$ & $<0.001$ & $0.55(0.40-0.75)$ \\
\hline $\begin{array}{l}\text { 14. In men, a collar size } 17 \text { in. or greater is associated with } \\
\text { OSA (true) }\end{array}$ & $76(28.7)$ & $134(36.5)$ & $210(33.2)$ & $<0.05$ & $0.70(0.50-0.98)$ \\
\hline 15. OSA is more common in women than men (false) & $164(61.9)$ & $239(65.1)$ & $403(63.8)$ & 0.404 & $0.87(0.63-1.21)$ \\
\hline 16. CPAP is the first line therapy for OSA (true) & $128(48.3)$ & $219(59.7)$ & $347(54.9)$ & $<0.01$ & $0.63(0.46-0.87)$ \\
\hline $\begin{array}{l}\text { 17. Less than } 5 \text { apneas or hypopneas per hour is normal in } \\
\text { adults (true) }\end{array}$ & $88(33.2)$ & $93(25.3)$ & $181(28.6)$ & $<0.05$ & $1.47(1.03-2.07)$ \\
\hline $\begin{array}{l}\text { 18. Cardiac arrhythmias may be associated with untreated } \\
\text { OSA (true) }\end{array}$ & $187(70.6)$ & $312(85.0)$ & $499(79.0)$ & $<0.001$ & $0.42(0.29-0.62)$ \\
\hline Mean (SD) percentage of knowledge items answered correctly & $53.5(14.4)$ & 60.4 (15.2) & $57.5(15.2)$ & $<0.001$ & \\
\hline
\end{tabular}

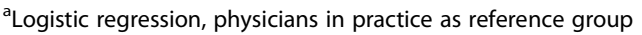

* $P$ for chi-square test comparisons between recent graduates and physicians in practice

We found that mean knowledge about OSA was 53.5\% among recent graduates, and there were no significant differences in mean knowledge scores by gender or university ownership. Our study demonstrated low levels of knowledge in recent medical graduates, similar to a previous study of Latin-American physicians already in practice [9].

Studies of recent medical graduates' knowledge of OSA, attitudes toward OSA and its management are not common.

When we compared the present study with that of a previously published study using OSAKA questionnaire, we found that the level of knowledge among medical school graduates in our country was higher $(53 \%$ compared with 43\%) [18]. In Saudi Arabia [16], medical students were assessed about their knowledge about sleep using the Assessment of Sleep Knowledge in Medical Education (ASKME) Survey [16]. Only 4.6\% of the respondents received a total score of $\geq 60 \%$ correct [16], showing very little knowledge about sleep and sleep disorders among medical students in selected schools in Saudi Arabia. We didn't find differences between Public or Private Universities.

Thus, assessing sleep medicine knowledge among medical students and recent graduates, there is a clear need for sleep medicine curriculum to be introduced during medical school.

The absence of differences in total knowledge scores in our sample where participants were educated (University 


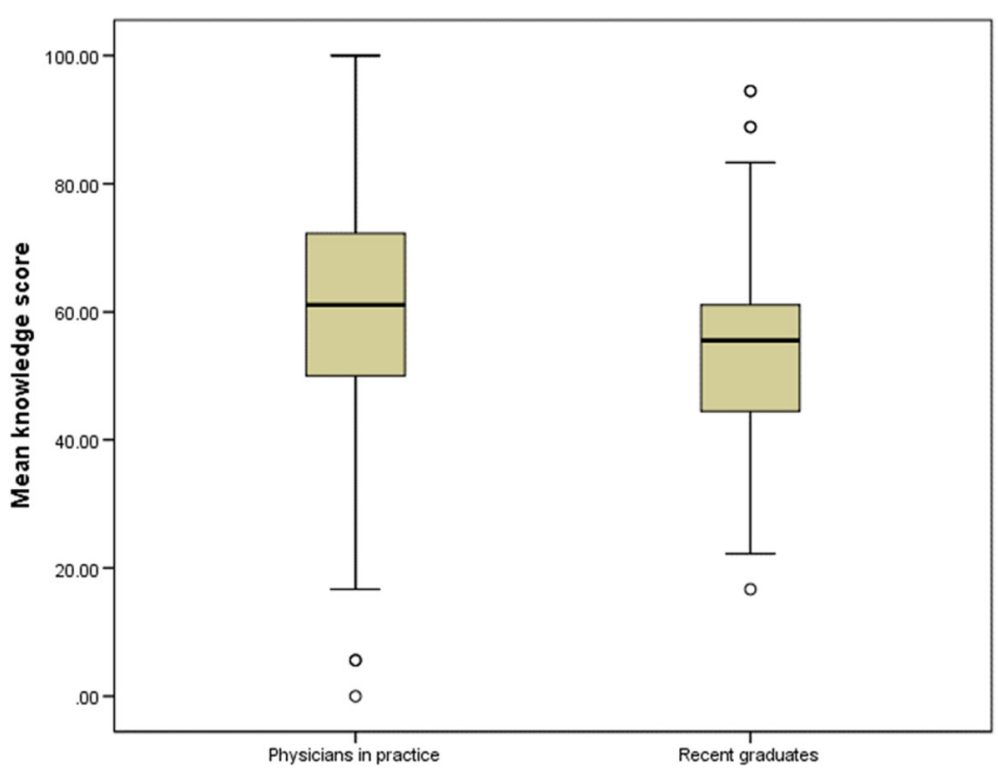

Fig. 2 Boxplot of percentage of knowledge items answered correctly OSAKA comparing recent graduates with practicing Physicians

Table 2 Percentages of recent medical graduates answering each knowledge item correctly by university ownership

\begin{tabular}{|c|c|c|c|}
\hline \multirow[t]{4}{*}{ Knowledge items } & \multicolumn{3}{|l|}{ University } \\
\hline & \multirow{2}{*}{$\begin{array}{l}\text { Private } \\
N=51\end{array}$} & \multirow{2}{*}{$\begin{array}{l}\text { Public } \\
N=214\end{array}$} & \multirow[t]{3}{*}{$p^{*}$} \\
\hline & & & \\
\hline & n (\%) & n (\%) & \\
\hline 1. Women with OSA may present with fatigue alone & $22(43.1)$ & $80(37.4)$ & 0.448 \\
\hline 2. Uvulopalatopharyngoplasty is curative for the majority if patients with OSA & $16(31.4)$ & $77(36.0)$ & 0.535 \\
\hline 3. The estimated prevalence of OSA among adults is between 2 and $10 \%$ & $21(41.2)$ & $100(46.7)$ & 0.474 \\
\hline 4. The majority of patients with OSA snore & $49(96.1)$ & $182(85.0)$ & $<0.05$ \\
\hline 5. OSA is associated with hypertension & $23(45.1)$ & $71(33.2)$ & 0.110 \\
\hline 6. An overnight sleep study is the gold standard for diagnosing OSA & $40(78.4)$ & $157(73.4)$ & 0.457 \\
\hline 7. CPAP therapy may cause nasal congestion & $12(23.5)$ & $78(36.4)$ & 0.080 \\
\hline 8. Laser-assisted uvuloplasty is an appropriate treatment for severe OSA & $9(17.6)$ & $58(27.1)$ & 0.163 \\
\hline 9. The loss of upper airway muscle tone during sleep contributes to OSA & $35(68.6)$ & $137(64.0)$ & 0.535 \\
\hline $\begin{array}{l}\text { 10. The most common cause of OSA in children is the presence of large } \\
\text { tonsils and adenoids }\end{array}$ & $43(84.3)$ & $185(86.4)$ & 0.693 \\
\hline $\begin{array}{l}\text { 11. A craniofacial and oropharyngeal examination is useful in the assessment } \\
\text { of patients of large tonsils and adenoids }\end{array}$ & $37(72.5)$ & $161(75.2)$ & 0.692 \\
\hline 12. Alcohol at bedtime improves OSA & $36(70.6)$ & $153(71.5)$ & 0.898 \\
\hline $\begin{array}{l}\text { 13. Untreated OSA is associated with a higher incidence of automobile } \\
\text { crashes }\end{array}$ & $29(56.9)$ & $98(45.8)$ & 0.155 \\
\hline 14. In men, a collar size $17 \mathrm{in}$. or greater is associated with OSA & $24(47.1)$ & $52(24.3)$ & $<0.01$ \\
\hline 15. OSA is more common in women than men & $28(54.9)$ & $136(63.6)$ & 0.253 \\
\hline 16. CPAP is the first line therapy for OSA & $29(56.9)$ & $99(46.3)$ & 0.173 \\
\hline 17. Less than 5 apneas or hypopneas per hour is normal in adults & $16(31.4)$ & $72(33.6)$ & 0.757 \\
\hline 18. Cardiac arrhythmias may be associated with untreated OSA & $34(66.7)$ & $153(71.5)$ & 0.497 \\
\hline Mean (SD) knowledge score (\% of items answered correctly) & $54.8(13.0)$ & $53.2(14.7)$ & 0.476 \\
\hline
\end{tabular}


Table 3 Differences between recent graduates and physicians in practice in mean (SD) scores on the importance of OSA and confidence in identifying and managing patients with OSA

\begin{tabular}{|c|c|c|c|c|}
\hline \multirow[t]{3}{*}{ Attitude items } & Total & Recent graduates & Physicians in practice & \multirow[t]{3}{*}{$p^{*}$} \\
\hline & $N=632$ & $N=265$ & $N=367$ & \\
\hline & Mean (SD) & Mean (SD) & Mean (SD) & \\
\hline Importance of OSA as a clinical disorder & $3.7(0.9)$ & $3.4(0.8)$ & $3.9(0.8)$ & $<0.001$ \\
\hline Important to identify patients with OSA & $3.7(0.9)$ & $3.4(0.8)$ & $3.9(0.8)$ & $<0.001$ \\
\hline Importance subscale score & $3.7(0.8)$ & $3.4(0.7)$ & $3.9(0.8)$ & $<0.001$ \\
\hline Confident identifying at-risk patients & $3.6(1.0)$ & $3.5(0.9)$ & $3.7(1.0)$ & 0.024 \\
\hline Confident managing patients with OSA & $3.1(1.1)$ & $3.3(1.0)$ & $2.9(1.1)$ & $<0.001$ \\
\hline Confident managing patients on CPAP & $2.7(1.1)$ & $2.8(1.0)$ & $2.5(1.1)$ & $<0.01$ \\
\hline Confidence subscale score & $3.2(0.9)$ & $3.3(0.9)$ & $3.0(0.9)$ & $<0.001$ \\
\hline
\end{tabular}

*Tests of significance were one-way analyses of variance

Public or Private) could be related to poor sleep curriculum during medical school regardless of school location. Multiple factors not measured in our study may be associated with a low knowledge score. Insufficient sleep curriculum could be one of the factors. In a multi-national study of medical schools [19], the authors identified prominent barriers to sleep education, including insufficient time devoted to sleep curriculum during the medical core program (32\%) and lack of qualified staff (24\%). The average amount of time devoted to sleep education was $2.5 \mathrm{~h}$, and $27 \%$ of medical schools did not provide any education about sleep medicine. Similarly, a study in Italy reported a mean of $2.5 \mathrm{~h}$ [20], and a study in Saudi Arabia reported a mean of $2.6 \mathrm{~h}$ of sleep education during medical school [16]. The latter study reported two principal barriers to incorporate sleep medicine into the curriculum: the topic has a lower priority and time constraints do not allow more time for incorporating sleep medicine into the

Table 4 Differences in recent medical graduates' mean (SD) scores on the importance of OSA and confidence in identifying and managing patients with OSA by university ownership

\begin{tabular}{llll}
\hline Attitude items & University & & \\
\cline { 2 - 4 } & $\begin{array}{l}\text { Private } \\
N=51\end{array}$ & $\begin{array}{l}\text { Public } \\
N=214\end{array}$ & $p^{*}$ \\
& mean (SD) & mean (SD) & \\
\hline $\begin{array}{l}\text { Importance of OSA as a clinical } \\
\text { disorder }\end{array}$ & $3.3(0.7)$ & $3.4(0.8)$ & 0.829 \\
$\begin{array}{l}\text { Important to identify patients } \\
\text { with OSA }\end{array}$ & $3.2(0.8)$ & $3.4(0.8)$ & 0.211 \\
$\begin{array}{l}\text { Importance subscale score } \\
\begin{array}{l}\text { Confident identifying at-risk } \\
\text { patients }\end{array}\end{array}$ & $3.3(0.7)$ & $3.4(0.7)$ & 0.415 \\
$\begin{array}{l}\text { Confident managing patients } \\
\text { with OSA }\end{array}$ & $3.5(0.9)$ & $3.5(0.9)$ & 0.697 \\
$\begin{array}{l}\text { Confident managing patients } \\
\text { on CPAP } \\
\text { Confidence subscale score }\end{array}$ & $2.9(1.1)$ & $2.8(1.0)$ & $0.08)$ \\
\hline
\end{tabular}

*Tests of significance were one-way analyses of variance curriculum [16]. In our country from 1 to $4 \mathrm{~h}$ had been dedicated about sleep medicine education.

In addition, knowledge is not only dependent on the amount of time devoted to sleep medicine in the curriculum, but also on how the subject is taught. For example, education focused on recognizing symptoms of fatigue/sleepiness, understanding the basic physiology of sleep and sleep-wake rhythms, and providing a basic overview of common sleep disorders, with an emphasis on screening, diagnosis, and treatment of these disorders, was found to result in greater improvement in sleep knowledge than a sham module listing random sleep facts and trivia presented in slides [21].

Our study demonstrated low levels of knowledge in recent medical graduates, similar to a previous study of Latin-American physicians already in practice [9]. Patients with symptoms of OSA present to nearly all doctors, irrespective of specialty, and a basic knowledge of OSA is considered essential to identify these patients for appropriate referral and treatment. Moreover, in this current study, we directly compared the scores between recent graduates and physicians in practice and found that recent graduates were significantly less likely than physicians in practice to report correct answers to 10 of 18 knowledge items on the OSAKA. This lack of knowledge about the epidemiology, diagnosis, and treatment of OSA in recent medical graduates has implications for patient care during residency training, as lack of knowledge is an impediment to the timely diagnosis of OSA and referral of patients to a specialist, and can lead to an increased risk for later complications. For instance, patients frequently consult for hypertension, but our students demonstrated little knowledge about the relationship between OSA and hypertension. This observation is consistent with the findings reported in a study of medical students in Nigeria [18].

Furthermore, recent medical graduates who were surveyed did not respond correctly that cardiac arrhythmias may be associated with untreated OSA. Such beliefs 
could possible delay referral of patients to a specialist to initiate CPAP, which is the preferred treatment for patients with severe OSA.

Interestingly, recent medical graduates reported higher mean scores about confidence managing patients with OSA and CPAP than physicians in practice, which could reflect some self-protection or social desirability bias among recent graduates.

A lack of confidence in managing patients with sleep complaints and deficits in sleep knowledge are barriers to quality of care for OSA patients and can be attributed to a lack of exposure to sleep medicine in undergraduate and postgraduate medical education curricula [22].

But these findings are problematic in light of the low level of actual knowledge about OSA and its treatment that recent graduates reported. Given our findings in this study, medical schools are challenged to add greater emphasis on sleep medicine to their curricula to better enable medical students and graduates to detect OSA in patients and initiate treatment or to refer these patients to specialists for further examination and treatment.

The few hours of sleep medicine generally taught in medical schools around the world reflect a widespread need to enrich the medical-school curriculum with sleep medicine topics $[18,19]$. Integrating more than a few hours of sleep medicine topics into the curriculum can better prepare students to identify and manage OSA during residency training, given the importance of the association between OSA and other life-threatening conditions $[4,5]$.

Future studies are needed to determine if incorporating OSA-focused educational interventios during medical school should help to improve recent medical graduates' knowledge about OSA.

Our study had some limitations. First, this was a cross-sectional survey, and we cannot infer causation from any of the associations we observed. We also cannot generalize our results to other countries where medical education about OSA might differ in important ways. However, different studies also reported low levels of physicians' knowledge about OSA diagnosis and treatment regardless of years of experience [12-17, 19-21].

However the strengths of our study include the use of a validated questionnaire $[18,19]$ and higher sample size. Future research could further validate the OSAKA by determining whether people with higher knowledge scores tend to appropriately refer patients at risk for OSA to get a sleep study. Improving medical school training on sleep disorders would likely increase the identification of persons at high risk of OSA and increase referral for consultation with expert sleep physicians [23].

Our next steps will be to focus future research on adding sleep medicine topics to the medical school curriculum and evaluating the impact of sleep medicine curricular change on physicians' practice patterns and patient outcomes.

\section{Conclusions}

Most of recent medical graduates in Ecuador did not know about OSA risk factors and appropriate management of OSA; not being able to recognize and appropriately refer patients at high risk of OSA for testing contributes to the under diagnosis of OSA and treatment. OSA-focused educational interventions during medical school should help to improve recent medical graduates' knowledge about OSA, its diagnosis and referral for treatment. The addition of sleep medicine education to the current medical school curriculum, as well as a greater number of hours of medical students' exposure to sleep education, could improve outcomes in patients with OSA.

\section{Abbreviations}

ANOVA: Analyses of variance; ASKME: Assessment of Sleep Knowledge in Medical Education; CPAP: Continuous positive airway pressure; OSA: Obstructive Sleep Apnea; OSAKA: OSA Knowledge and Attitudes; PSG: Polysomnography; SD: Standard deviation

\section{Acknowledgements}

The authors acknowledge the guidance and knowledge imparted by the MECOR Program for this study, especially from Sonia Buist MD and Ana Menezes MD. Finally, we are also very grateful for all the support provided by Erick Calero, José Martín Vilema, and Michell Torres, as well as to all members of the RespiraLab team.

\section{Funding}

Not applicable.

\section{Availability of data and materials}

The datasets used and/or analysed during the current study are available from the corresponding author on reasonable request.

\section{Authors' contributions}

JCC: Conceptualization, data acquisition and analysis, drafting and review of manuscript and approval of final manuscript. ICO, DBJ, IS, DSR, JC, AC, EV: Conceptualization, data analysis, drafting, and review of manuscript and interpretation of results and approval of final manuscript. AFG, FB: Conceptualization, data acquisition and review of manuscript and approval of final manuscript. All authors read and approved the final manuscript.

Ethics approval and consent to participate

The present study was approved by Ethic Committee of Clinica Kennedy.

Consent for publication

Not applicable.

Competing interests

The authors declare that they have no competing interests.

\section{Publisher's Note}

Springer Nature remains neutral with regard to jurisdictional claims in published maps and institutional affiliations.

\section{Author details}

${ }^{1}$ Universidad Espiritu Santo, Samborondon, Ecuador. ${ }^{2}$ Respiralab Research Group, Respiralab, Guayaquil, Ecuador. ${ }^{3}$ Department of Medicine, Washington University School of Medicine, St. Louis, MO, USA. ${ }^{4}$ Department of Medicine, University Federal of Sao Paulo, Sao Paulo, Brazil. ${ }^{5}$ School of Medicine, University of Heidelberg, Heidelberg, Germany. ${ }^{6}$ Centro de Investigación en Salud Pública y Epidemiologia Clínica, Facultad de Ciencias de la Salud Eugenio Espejo, Universidad Tecnológica Equinoccial, Quito, Ecuador. 
Received: 2 November 2017 Accepted: 29 January 2018

\section{Published online: 21 February 2018}

\section{References}

1. Riha RL. Clinical assessment of the obstructive sleep apnoea/hypopnoea syndrome. Ther Adv Respir Dis. 2010;4(2):83-91.

2. Tishler PV, Larkin EK, Schluchter MD, Redline S. Incidence of sleepdisordered breathing in an urban adult population: the relative importance of risk factors in the development of sleep-disordered breathing. JAMA. 2003;289(17):2230-7.

3. Young T, Peppard PE, Gottlieb DJ. Epidemiology of obstructive sleep apnea: a population health perspective. Am J Respir Crit Care Med. 2002;165(9):1217-39.

4. Malhotra A, White DP. Obstructive sleep apnoea. Lancet. 2002;360(9328):237-45.

5. Budhiraja R, Budhiraja P, Quan SF. Sleep-disordered breathing and cardiovascular disorders. Respir Care. 2010;55(10):1322. -32-2

6. Dutt N, Janmeja AK, Mohapatra PR, Singh AK. Quality of life impairment in patients of obstructive sleep apnea and its relation with the severity of disease. Lung India. 2013;30(4):289-94.

7. Giles TL, Lasserson TJ, Smith BH, White J, Wright J, Cates CJ. Continuous positive airways pressure for obstructive sleep apnoea in adults. Cochrane Database Syst Rev. 2006;3:CD001106.

8. Marin JM, Agusti A, Villar I, Forner M, Nieto D, Carrizo SJ, et al. Association between treated and untreated obstructive sleep apnea and risk of hypertension. JAMA. 2012;307(20):2169-76.

9. Cherrez Ojeda I, Jeffe DB, Guerrero T, Mantilla R, Santoro I, Gabino G, et al. Attitudes and knowledge about obstructive sleep apnea among Latin American primary care physicians. Sleep. 2013;14(10):973-7.

10. Hayes SM, Murray S, Castriotta RJ, Landrigan CP, Malhotra A. (Mis) perceptions and interactions of sleep specialists and generalists: obstacles to referrals to sleep specialists and the multidisciplinary team management of sleep disorders. J Clin Sleep Med. 2012;8(6):633-42.

11. Tamay Z, Akcay A, Kilic G, Suleyman A, Ones U, Are GN. Physicians aware of obstructive sleep apnea in children? Sleep Med. 2006;7(7):580-4.

12. Schotland HM, Jeffe DB. Development of the obstructive sleep apnea knowledge and attitudes (OSAKA) questionnaire. Sleep Med. 2003;4(5):443-50.

13. Schotland HM, Jeffe DB. Erratum to "development of the obstructive sleep apnea knowledge and attitudes (OSAKA) questionnaire" [sleep medicine 4 (2003) 443-450]. Sleep Med. 2008;9(6):705.

14. Southwell C, Moallem M, Auckley D. Cardiologist's knowledge and attitudes about obstructive sleep apnea: a survey study. Sleep Breath. 2008;12(4):295-302

15. Uong EC, Jeffe DB, Gozal D, Arens R, Holbrook CR, Palmer J, et al. Development of a measure of knowledge and attitudes about obstructive sleep apnea in children (OSAKA-KIDS). Arch Pediatr Adolesc Med. 2005;159(2):181-6

16. Almohaya A, Qrmli A, Almagal N, Alamri K, Bahammam S, Al-Enizi M, et al. Sleep medicine education and knowledge among medical students in selected Saudi medical schools. BMC Med Educ. 2013;13(1):133.

17. Luo M, Feng Y, Li T. Sleep medicine knowledge, attitudes, and practices among medical students in Guangzhou, China. Sleep Breath. 2013:17(2):687-93.

18. Ozoh OB, Iwuala SO, Desalu OO, Ojo OO, Okubadejo NU. An assessment of the knowledge and attitudes of graduating medical students in Lagos, Nigeria, regarding obstructive sleep apnea. Ann Am Thorac Soc [Internet] 2015;12(9):1358-1363. Available from: https://doi.org/10.1513/AnnalsATS. 201412-5610C

19. Mindell JA, Bartle A, Wahab NA, Ahn Y, Ramamurthy MB, Huong HTD, et al. Sleep education in medical school curriculum: a glimpse across countries. Sleep Med [Internet]. 2017;12(9):928-31. Available from: https://doi.org/10. 1016/j.sleep.2011.07.001

20. Bonanni E, Maestri M, Fabbrini M, Cirignotta F, Ferini-Strambi L, Gigli GL, et al. Sleep education in Italy. Sleep Med. 2012;13(4):450.

21. Salas RE, Gamaldo A, Collop NA, Gulyani S, Hsu M, David PM, et al. A step out of the dark: improving the sleep medicine knowledge of trainees. Sleep Med. 2013;14(1):105-8

22. Boulet L-PL-P, Bourbeau J, Skomro R, Gupta S. Major care gaps in asthma, sleep and chronic obstructive pulmonary disease: a road map for knowledge translation. Can Respir J. 2013;20(4):265-9.

23. Haponik EF, Frye AW, Richards B, Wymer A, Hinds A, Pearce K, et al. Sleep history is neglected diagnostic information. J Gen Intern Med [Internet]. 1996;11(12):759-761. Available from: https://doi.org/10.1007/BF02598994

\section{Submit your next manuscript to BioMed Central and we will help you at every step:}

- We accept pre-submission inquiries

- Our selector tool helps you to find the most relevant journal

- We provide round the clock customer support

- Convenient online submission

- Thorough peer review

- Inclusion in PubMed and all major indexing services

- Maximum visibility for your research

Submit your manuscript at www.biomedcentral.com/submit 